\title{
Educação Inclusiva e Diferenciada Indígena
}

O trabalho intitulado "Educação Inclusiva e Diferenciada Indígena ", propõe uma ampliação da compreensão da educação inclusiva.Educação inclusiva refere-se a iserção de alunos com deficiência na rede regular de ensino. O Trabalho porém, expande esta perspectiva e insere a educação indígena como ponto de reflexão central. Para isso, muda-se todo o entendimento anterior de educação inclusiva e apresenta-se um novo plano de educação, ou seja, a inclusão da educação diferenciada para povos indígenas.

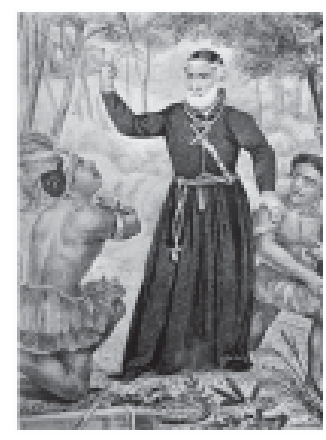

Gerson Alves da Silva Júnior

Estudante do $2^{\circ}$ ano do curso de Psicologia do Instituto de Psicologia da Universidade

Federal de Alagoas (UFA)

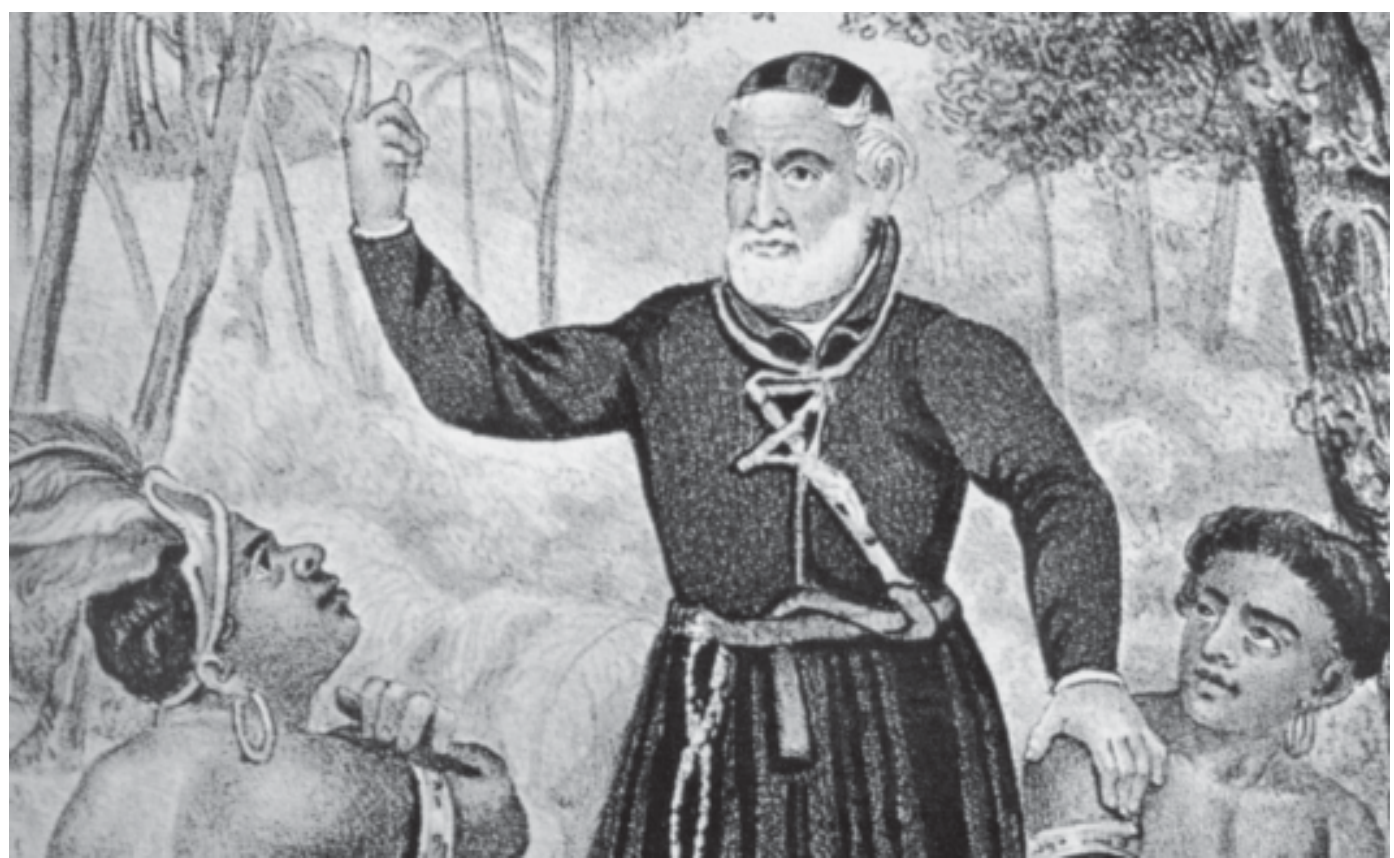

"A meta é incluir todos os alunos, ou seja, garantir um ensino de qualidade para absolutamente todos: deficientes, pobres, negros, marginais, ninguém deve ser excluído."

Refletindo nas palavras acima da professora Marilene Ribeiro do Santos, Secretária de Educação Especial do Ministério da Educação e Cultura - MEC, referindo-se à educação inclusiva $^{1}$, verifiquei que o termo inclusão toma uma conotação e denotação bem mais ampla do que a simples inserção de deficientes físicos e mentais na rede regular de ensino.
A frase supracitada abriu um leque de novas possibilidades e ofereceu suporte de inovações no que toca a aplicabilidade da educação inclusiva. De outra forma, ou seja, sem um ser educação inclusiva, torna-se inexeqüível qualquer tentativa de inocular novas perspectivas e aplicações do termo que tratamos.

Desta forma, venho propor esta nova panorâmica da educação inclusiva: educação nas comunidades indígenas. Isto, acreditando que de forma alguma estou desfocado, pois percebo olhar mais amplo do que realmente venha a 
que o registro atual do que seja educação inclusiva não exclui ninguém, muito pelo contrário funciona de infra-estrutura.

As razões que me conduziram a este assunto são tão amplas e diversas que esgotaria os limites desta monografia tentando expô-las. Aqui cabe apenas dizer que meu contato com os problemas desses povos levaram-me a crer que a educação é base fundamental para o processo de reconquista da dignidade dos mesmos. Esta é a principal razão da construção do trabalho que se segue.

Ponho em foco a Psicologia enquanto compromisso social referente a educação inclusiva, coadunando-se com a educação nas comunidades indígenas, na pretensão de analisar e estudar um pouco mais de perto seus problemas "educacionais", sem, no entanto, descartar o intuito de propagar a todos os problemas subjacentes a estes, na esperança que sirvam ao menos de motivo de reflexões.

Meu objetivo geral é verificar a aplicabilidade e principalmente a necessidade da contribuição da Psicologia na educação das comunidades indígenas. É cabível lembrar que a educação nesses povos não deixa, em momento algum, de se enquadrar dentro dos parâmetros da educação inclusiva. A este fato, isto é, os limites devidos a definições do termo educação inclusiva, além de outros aspectos correlacionados, desprenderei um capítulo desta monografia; capítulo este que servirá de alicerce oferecendo os subsídios necessários para o restante do trabalho, pois será a base de apoio e o suporte de relação e discussão entre a educação indígena (que é o assunto que pretendo evidenciar dentro do tema) e o tema proposto (Psicologia e Compromisso Social Educação Inclusiva: desafios, limites e perspectivas).

Para realização desta monografia, utilizei-me de pesquisa bibliográfica (livros, revistas, jornais, artigos) e entrevistas com profissionais da área (educadores indígenas, missionários ${ }^{2}$ etc.). Por conta desta situação podemos afirmar que a presente monografia encontra-se dentro dos padrões de um fundamento de uma pesquisa exploratória.

Os objetivos específicos deste trabalho são os seguintes: refletir sobre o termo educação inclusiva, atentando para possibilidades de novas perspectivas a respeito do mesmo, correlacionando e oferecendo espaço para o assunto que se deseja tratar mais diretamente (educação nas comunidades indígenas). Tentar, com base em bibliografia específica, fazer uma breve recapitulação do processo de educação dos povos indígenas na história. Em seguida, verificar em que pode contribuir a psicologia na educação dentro e fora das comunidades indígenas. E por fim, concluir fazendo uma ligeira análise de tudo o que foi debatido.

Desta forma, o trabalho subdivide-se em cinco capítulos: educação inclusiva: definições e possibilidades; história da educação nas comunidades indígenas; contribuição da Psicologia dentro das comunidades indígenas; contribuição da Psicologia fora das comunidades indígenas; e conclusão.

\section{Educação Inclusiva: Definições e Possibilidades}

No MEC existe hoje um comitê nacional de educação indígena no qual sua coordenadora Ivete Campos põe em prática o desejo antigo de uma educação diferenciada, onde possa-se valorizar as diferenças culturais de maneira a utilizá-las em prol do desenvolvimento dos povos indígenas.

Existe também no MEC uma política de educação especial, onde há um direcionamento de atenção aos portadores de deficiência. Todavia, este direcionamento não implica num dogmatismo no que diz respeito à educação inclusiva, pois, na verdade, na década de 70, quando o MEC assumiu que a clientela da educação especial é a que "requer cuidados especiais no lar, na escola e na sociedade", não definiu aí o que seria educação inclusiva. As sementes da educação inclusiva só estariam realmente lançadas quando o Brasil, finalmente, segundo Ana Jover (1999), participou da Conferência Mundial Sobre Educação para Todos, na cidade de Jomtiem, na Tailândia, em 1990.

O objetivo da Conferência foi despertar a necessidade da educação de qualidade para todos. Isto é, como disse a secretária de educação especial do MEC: "incluir todos os alu-
1- Marilene Ribeiro apud: JOVER, Ana. Inclusão: qualidade para todos. in: Revista Nova Escola, Ano XIV, $n^{\circ} 123$ junho 1999.

2-O Conselho Indigenista Missionário - CIMI/ NE, por meio de Jorge Vieira, contribuiu enormemente nesta obra. 
nos (...), absolutamente todos: deficientes, pobres, negros, marginais (...)". No entanto, é sabido por todos que o termo educação inclusiva vem sendo aplicado nos dias hodiernos no sentido único de introdução de alunos com necessidades especiais na rede regular de ensino.

Discorramos um pouco sobre o termo em evidência: Inclusiva (inclusão), que inclui, abrange; palavra derivada do verbo incluir, que por sua vez está etimologicamente ligado ao termo latino incluire. Originariamente significaria inserir, introduzir, acrescentar, podendo significar também, abranger, compreender, envolver, implicar. Segundo Roquette (1928), seria equivalente ao verbo incluir a frase "COlocar também". Ora o termo inclusão, pois então, significaria em última instância, no contexto em que nos encontramos, introduzir ${ }^{3}$ alguém ou alguma coisa em algo ou algum lugar. Não nos restam dúvidas de que este algo ou algum lugar, seja a educação ou a escola; o problema é - que educação? E que escola?

Que educação? A resposta provavelmente já é conhecida por todos: educação de qualidade. Educação de qualidade seria aquela capaz de oferecer ao indivíduo, os subsídios básicos e necessários a um(a) convívio/sobrevivência social harmônico(a) e progressista. É válido ressaltar que quando falamos aqui de educação, em certo sentido, nos referimos a ensino.

Que escola? A escola é o lugar por excelência de ensino, de educação. Portanto, a escola que aludimos neste estudo deve ser a escola que ofereça um ensino de qualidade, ou seja, uma educação de qualidade. Daí a impossibilidade de separar aqui educação de escola e vice-versa. Sendo pois então, educação de qualidade aquela que é capaz de inserir o indivíduo (educando) no convívio social de seu grupo ${ }^{4}$, podemos concluir que escola aqui implica necessariamente numa instituição oficial que confira ao sujeito os ensinamentos essenciais para uma vivência tranqüila e desenvolvimentista na sociedade que este se configura.

Portanto, de nossa conclusão do termo inclusão - introduzir alguém ou alguma coisa em algo ou algum lugar -, podemos avançar e afirmar que inclusão significaria agora para nós

neste contexto: introduzir alguém numa escola que ofereça um ensino de qualidade. É bom observar que refiro-me só a introduzir alguém, e suprimo o alguma coisa. Faço isto devido a conotação que a frase toma, pois, não podemos ensinar a coisas. Ensinamos a seres humanos e estes são sempre alguém, e não algumas coisas.

Partamos agora para analisar quem é ou quem são estes seres humanos cuja educação inclusiva pretende.

Se tomarmos por base os marcos que semearam o surgimento da educação inclusiva, como por exemplo, a Conferência Mundial Sobre Educação para Todos (1990), concluiremos que a educação inclusiva pretende a TODOS.

Se partirmos do princípio etimológico do termo educação inclusiva, veremos que este em si não define nem especifica ninguém. Mas, por si só, pretende incluir alguém na educação, e sabendo-se que pela Constituição Federal, Cap. III, seção I, art. 205, a educação é “(...) direito de todos e dever do Estado (...)", podemos concluir que a educação inclusiva pretende a TODOS.

Se avaliarmos porém o contexto atual no qual o termo educação inclusiva está inserido, isto é, referindo-se sempre à inserção de alunos especiais na rede de ensino regular, concluiremos que este possui um espaço de aplicação específico. Bem que poderíamos realmente chegar a esta conclusão e dar por encerrado este assunto, mas lamento informar que isto não será possível. Pois, se formos avaliar o contexto atual para chegarmos ao real significado do termo ${ }^{6}$, temos que analisar os discursos nos quais geralmente este termo é empregado. E nesta própria monografia já inserimos alguns discursos, os quais dão margem para uma inclusão de todos, por exemplo o discurso da professora Marilene Ribeiro do Santos, Sec. de Educ. Especial do MEC:

"A meta é incluir todos os alunos, ou seja, garantir um ensino de qualidade para absolutamente todos: deficientes, pobres, negros, marginais, ninguém deve ser excluído."

Outro fato interessante que podemos incluir aqui é o da Revista Nova Escola - junho 1999, 
onde a matéria de capa é: “Inclusão: uma utopia possível". Já na capa podemos encontrar o seguinte escrito: "Entenda por que a convivência dos diferentes amplia os horizontes escolares e sociais de TODOS" ${ }^{\prime 7}$. E por fim, o tema da matéria, que não é de surpreender que seja: "Inclusão: qualidade para TODOS" ${ }^{8}$.

Disto tudo que vimos até agora podemos compreender que, a menos que TODOS não signifique TODOS, estaríamos errados em concluir que educação inclusiva pretende a TODOS.

Quero ressaltar que realmente a atual nomenclatura pode possuir espaço e significado específico. Mas para isto seria necessário, além de uma definição mais exata desta especificidade, um ponderamento nos discursos proferidos. E caso houvesse, seria necessário um direcionamento para essa especificidade e este ponderamento, quando o termo fosse aplicado (em concursos, por exemplo).

Na verdade, o que quero expor aqui é que o termo educação inclusiva por si só, apenas nos diz que TODOS devem ser incluídos numa educação de qualidade (entenda-se aqui educação de qualidade, nos parâmetros já expostos), nem que esta educação, para ser de qualidade deva ser diferenciada.

Simplificando tudo que foi dito até agora, quero colocar que não consiste em erro a atual aplicação do termo. Mas não podemos negar que este, num sentido geral é mais amplo, abarcando também novas possibilidades/perspectivas. Isto é, não se LIMITA a sua atual aplicação. Resta agora ao profissional da área aceitar, ou não, estes novos DESAFIOS.

Acreditando ter sido exposto suficientemente e redundantemente a significação do termo educação inclusiva - que aqui significaria a inclusão de todos na educação, podendo ser esta diferenciada ou tradicional. Necessário se faz agora direcionar a atenção para esta nova possibilidade: educação inclusiva e diferenciada nas comunidades indígenas.

Pretendo inserir uma nova ideologia, todavia - e quero que isto fique bem claro -, esta não é uma ideologia de confronto com a atual definição de educação diferenciada do MEC para os povos indígenas. Pois, na verdade, como veremos no capítulo terceiro, minha discussão encontra-se fora da proposta de currículo escolar para as comunidades indígenas. Desejo somar e não subtrair ou dividir, isto é, anseio acrescentar novas idéias que possam contribuir para o desenvolvimento destas etnias.

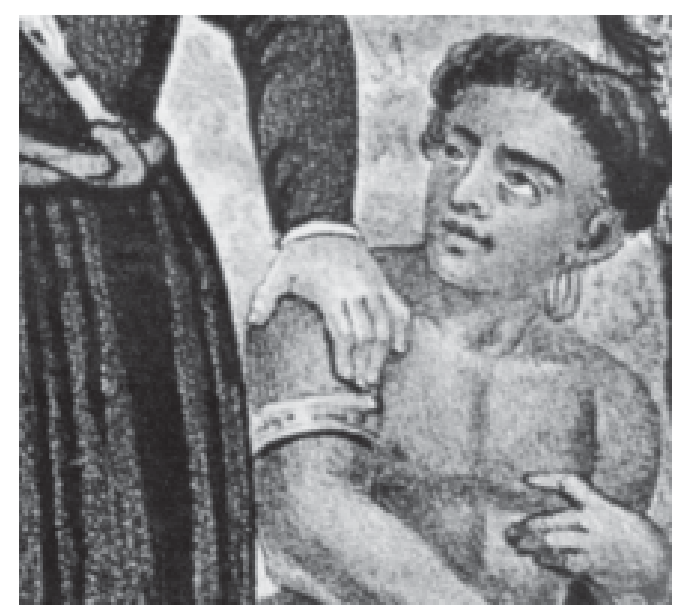

Portanto, meu desenvolvimento do termo educação inclusiva pretendia, nada mais nada menos, mostrar a importância real da inserção dos povos indígenas no "cardápio" da educação, que neste caso, para ser de qualidade, deve ser diferenciada.

Desta forma, finalizamos este capítulo, onde tentei alargar a compreensão do que seja educação inclusiva para que, com isto, possa-se expor o objetivo real do trabalho: verificar a aplicabilidade e principalmente a necessidade da contribuição da Psicologia na educação das comunidades indígenas. Espero que este capítulo seja um alicerce firme para suportar o peso da estrutura que se segue.

\section{História da Educação Nas Comunidades Indígenas}

Sem entrar em pormenores a respeito das intenções portuguesas, passemos a analisar brevemente o processo educativo dos povos indígenas durante a história da colonização (1532 D.C.) até os dias atuais.

Segundo Gilberto Freire (1980), no Brasil da época da colonização não havia reis de Cananor, sobas ${ }^{9}$ de Sofala, nem sedas, tape-
7 - Os grifos são meus.
8- Os grifos são meus.

9 - Nome dado aos reis ou chefes de tribos africanas. 
tes, pérolas ou rubis. Somente Matas virgens e índios, dormindo em redes ou no chão e alimentando-se da caça ou da pesca.

Escola é coisa de "homem branco". Educação é patrimônio da humanidade. Todos os povos, em todas as épocas, sempre tiveram suas formas de transmissão do conhecimento, seja por via oral (por meio de contos e fábulas); ou por outros meios e mecanismos. Com os índios não era diferente, de maneira própria e independente, também se transmitia o conhecimento.

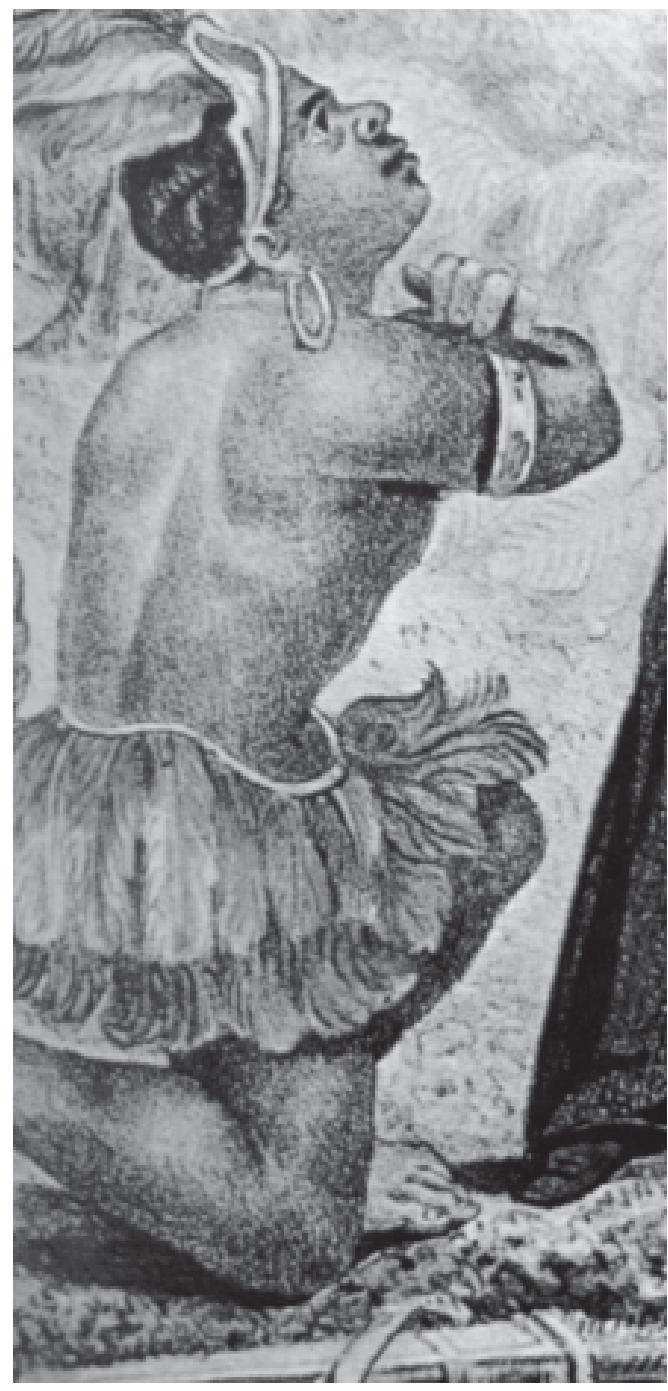

Porém, no contato de duas culturas, onde uma é mais primitiva ${ }^{10}$ e outra mais avançada tecnicamente, quase sempre a segunda procura destruir ou aniquilar na primeira tudo o que se supõe ser contrário à moral ou aos interesses dos dominadores. Assim fizeram os jesuí- tas educando o curumim à maneira dos europeus. (Gilberto Freire, 1980).

Os jesuítas, foram os primeiros educadores digo educadores do padrão europeu - que o Brasil e a América conheceu. No entanto, seus métodos educativos de nada valeram para os detentores do conhecimento indígena (os índios adultos). Assim, tentou-se sondar aquilo de mais frágil, em termos de conhecimento, que um povo pode ter: suas crianças.

As crianças são como um campo fértil, tudo que lhes é cultivado surte resultado. Os jesuítas sabiam disto e utilizando-se de teatros, presentes e outros, conquistou para si as crianças indígenas (curumins). O curumim tornou-se, assim, cúmplice do invasor na obra de eliminar à cultura nativa os seus elementos mais originais.

"Tornou-se inimigo dos pajés, da dança, dos maracás sagrados, das sociedades secretas. E deu-se, então, uma verdadeira inversão dos princípios: o filho tomou o encargo de educar o pai"11.

Mais tarde, com as primeiras escolas jesuítas, os curumins eram educados em companhia dos meninos europeus, como atesta Freire. Não havia segregações raciais. "O pátio dos colégios foi assim um ponto de encontro das duas culturas".

Formavam-se as missões (a primeira surgiu na época do governo de Mem de Sá), que tinham o encargo de catequizar e educar os silvícolas. Neste período, tribos inteiras se deixavam catequizar. Os gentios se tornavam cristãos, com conseqüente abandono de seus deuses e tradições seculares. A partir deste momento muitas tribos nômades passaram ao sedentarismo; muitos guerreiros passaram à pacatez, à passividade. Aprendeu-se a ler, escrever, trabalhar regularmente, "rezar" e em alguns casos a comercializar. (Souza, 1992).

No entanto, não devemos nos escandalizar com o trabalho dos jesuítas no Brasil e na América espanhola. Pois, assim como nós, eles eram cheios de boas intenções, e não pretendiam (pelo menos a maioria), a destruição do índio, e sim sua civilização. O problema é que, não foi detectado que, na imensa maioria dos casos, a introdução do silvícola na civilização 
era sinônimo de morte, que quando não era real, era cultural.

Os jesuítas, na realidade, podem ser reconhecidos historicamente como os maiores defensores das causas indígenas. Fizeram de sua vida sangue, sangue derramado pela liberdade e valorização dos índios (exemplo disto foi o episódio dos Sete Povos das Missões). No que puderam - pois, eram sujeitos a um interesse maior: as pretensões do Estado ${ }^{12}$ - conservaram a cultura indígena, inclusive a língua (o tupi). Além disto, destacaram-se vários padres jesuítas na apologia indígena, entre eles podemos citar José de Anchieta e Antonio Vieira. O maior erro da educação jesuíta talvez tenha sido o fato de fazer os silvícolas acreditarem que existiam "homens bons", e de pacificarem os índios. Pois, na época das bandeiras, os bandeirantes preferiam atacar os índios catequizados, porque estes, na maioria, já conheciam o português (língua) e eram mais pacíficos.

Além disso, o problema se agravou ainda mais com a expulsão dos jesuítas do Brasil (1760), por ordem de Sebastião José de Carvalho e Melo (Marquês de Pombal). Por conta da expulsão, intensificaram-se a exploração, perseguição e destruição destes povos e de suas culturas. Proibiu-se o ensino do tupi ${ }^{13}$, e a política de "integração" do índio a sociedade com sua conseqüente deculturação foi reforçada.

Foram incontáveis as perdas dessa época colonial: invasões, massacres, destribalizações, reduções, aldeamentos, deculturação, etnocídio, escravismo, exclusão etc. A educação até aqui, com raríssimas exceções, serviu mais de máquina administrativa para espoliação dos povos do que força desenvolvimentista.

No Brasil Imperial, a coisa não foi diferente e os massacres continuaram, até a época do Brasil República. Em 1914, já no período republicano uma novidade: a criação do Serviço de Proteção ao İndio (SPI). Mas quem achar que este órgão tinha a finalidade de proteger o índio, está tremendamente enganado, pois a proteção está só no nome. A finalidade do SPI era integrar os índios à sociedade brasileira. Não há problema algum em integrar índios à sociedade, o problema é que na definição, índio integrado não é mais índio. Para esta fina- lidade (de integração), utilizou-se de vários meios, e principalmente da educação. A História, por exemplo, ainda hoje é contada de uma perspectiva unicamente portuguesa, mesmo sabendo-se que o povo brasileiro não é só constituído de descendentes de portugueses puros.

Como vimos na República, continua-se a mesma política, ou seja, integração com conseqüente deculturação. Vale frisar que a educação exerce importante papel nesta prática.

"Os índios continuavam sendo expulsos de suas terras e exterminados. Os que se integravam (...), trabalhavam como vaqueiros, canoeiros, caçadores, guias e lavradores, nas pequenas roças (...). Ficavam durante muito tempo longe de suas aldeias, de suas mulheres, de seus filhos (...), quando voltavam, nada mais encontravam" ${ }^{\prime 14}$.

Durante o governo militar surge a Funai - Fundação Nacional do Índio (1967). Era a entidade encarregada de tutelar o índio, gerir o seu patrimônio, prestar-lhe assistência educacional etc. A Funai existe até os dias de hoje e quem acredita que ela presta um bom serviço ao índio precisa ver as denúncias feitas por Paulo Suess, em seu livro "Calice e Cuia", onde este, relata verdadeiras omissões da Funai.

Ainda no livro de Suess, encontramos o relato de funcionários da Funai, que tentam por em prática sua real política: "integrar" o índio à sociedade. A Funai, segundo o mesmo autor, elenca três categorias de índios: isolados, aqueles que possuem poucos contatos exteriores; semi-integrados, que se reconhecem como índios, mas comunicam-se e muitas vezes vivem como "brancos"; e integrados, os que estão completamente inseridos na sociedade, de maneira que não são mais índios, nem se reconhecem como tal.

Atualmente a educação indígena saiu das mãos da Funai e passou a ser administrada pelo MEC. Este propõe aquilo que os índios reivindicavam desde tempos "imemoriais": uma educação diferenciada. O problema é que depois de tantas invasões, etnocídios, massacres, expropriações, destribalizações, "cate-
13 - o ensino foi proibido por força de um decreto em 1758 durante a perseguição do Marquês de Pombal aos jesuitas.

14-SOUZA, Osvaldo Rodrigues. História do Brasil. Vol. 2, $19^{\circ}$ ed., São Paulo: Ática, 1992. 
queses", proletarizações, discriminações, preconceitos, exclusões etc. fica difícil saber que povo ainda tem capacidade de administrar suas diferenças, se é que estas ainda são reconhecidas. Fica complicado valorizar o que se tem, quando se parece não ter mais nada. Mas, se tudo nos reduz ao nada, do nada devemos partir.

\section{Contribuição da Psicologia Dentro das Comunidades Indígenas}

Reimão (1978), define a Psicologia enquanto ciência como:

“a procura de um conhecimento objetivo da vida mental. Os acontecimentos psíquicos não se encadeiam ao acaso. Trata-se de descobrir as suas leis e os seus efeitos sobre os comportamentos humanos (...)."

Ora, sendo a Psicologia a ciência do comportamento, quem melhor do que o psicólogo poderia desenvolver a sensibilidade de interpretar a riqueza de cada ação humana, o valor das expressões, a importância e o perigo das inter-relações. O sociólogo foca-se no social e deixa de lado o individual. O antropólogo, estuda a cultura das diversas etnias, sempre procurando enfocar o valor e a importância desta. Mas, o psicólogo, perpassando pela Sociologia e pela Antropologia, procura desenvolver seu trabalho verificando não só o fenômeno social, mas quanto este fenômeno influencia o individual e quanto o individual atua no social; isto, sem deixar de lado a importância da cultura de cada povo. Além do mais, o psicólogo é o profissional responsável por estudar os processos pelos quais se internalizam os conceitos, como se dá a formação destes, e a importância ou relevância dos mesmos. Ou seja, o estudo dos processos cognitivos no geral, são de encargo do psicólogo.

A educação nas comunidades indígenas, como vimos no capítulo anterior, sempre foi uma educação que visava "integrar" o índio na sociedade brasileira. Mas, por falta de um olhar profissional (isto desconsiderando outros fatores, como as intenções das classes dominantes), faltou uma definição mais precisa do que seria integração. Pois, esta não pode ser sinônimo de etnocídio.
Desta forma, coloquemos em prática o que a psicologia tem a oferecer, para resgatar ou manter, a identidade de um povo. Pois, todos hão de convir que a identidade cultural é necessidade não só psicológica, mas filosófica, antropológica, sociológica, histórica...

Dentro das comunidades indígenas, há uma necessidade da atuação da Psicologia, principalmente, da Psicologia Social. À vista de que, é o psicólogo social que compreende melhor como as pessoas influenciam e são influenciadas. Sem falar que a Psicologia Ambiental, também seria de máxima importância, no entanto, aqui incluirei o papel do psicólogo ambiental dentro do psicólogo social, visto que a Psicologia Ambiental, toma como referencial teórico a Psicologia Social.

Primeiramente, a grande necessidade da contribuição da Psicologia dentro da educação dos povos indígenas, está no fato de avaliar as possíveis conseqüências deste acontecimento novo, pois, educação institucionalizada na maioria dessas comunidades, é algo recente. Um exemplo paralelo do perigo da falta de uma avaliação anterior que podemos citar aqui, é a ação praticada pelos jesuítas no início da colonização, onde estes persuadiram os índios Guarani ${ }^{15}$ que viviam em malocas ${ }^{16}$ (nessas todos viviam juntos) a construírem casas ${ }^{17} \mathrm{se}$ paradas, onde passava-se a residir somente o núcleo familiar; este ocorrido, possibilitou aos índios daquela época a construção de uma individualidade tão sólida e repentina, que quase beirava a um egoísmo esnobe, pois quebrou-se, em parte, nesta sociedade, aquilo que ela possuía de mais significativo: a fraternidade e o senso de igualdade, que eram estimulados constantemente pelo convívio (morada) comunitário real, visto que tudo era compartilhado anteriormente, até mesmo a cozinha.

Cito este exemplo acima, pois na atualidade, por mais absurdo que pareça, muitas comunidades enfrentam problemas semelhantes, só que com a educação. Podemos evocar aqui o evento da inclusão dos índios do vale do Xingú ${ }^{18}$ na educação. Lá o cargo mais disputado das tribos, não é mais o de cacique, mas o de professor ${ }^{19}$. Esta mudança pode acarretar várias transformações no contexto social e cultural daquele povo. Pois, antes todos eram professores, e todos tinham o que ensinar; hoje o ensino é exclusividade de alguns. 
"A história anda. Anda... Não dá saltos"

Não quero estancar um processo natural de evolução, quero na verdade é que este processo seja o mais harmônico possível. E aqui vai outra tarefa para a psicologia. Isto é, todo um trabalho psicológico com estes novos educadores. Já que continuamos a fazer o que os jesuítas faziam no início da colonização: educar os índios da mesma forma que educamos nossos filhos.

Quero ressaltar que quando coloco que continuamos a educar da mesma forma que os jesuítas, não estou ignorando a proposta curricular do MEC de uma educação diferenciada. É que na verdade, o que desejo problematizar, não é o fato do currículo escolar, e sim a própria estruturação do que se entende chamar por escola e por professor. Pois, já é sabido que escola não é coisa de índio e professor muito menos.

Portanto, a meu ver, é o psicólogo ${ }^{20}$ que possui a acuidade de filtrar, de adaptar e muitas vezes transformar as organizações necessárias ao desenvolvimento humano, sem no entanto ferir ou destruir a cultura de cada povo, construída no decorrer de século (ou milêniOS).

De outra forma, ou seja, acreditando-se que não existe uma maneira diferente de alavancar o processo de educação indigenista, além destes oferecidos até o momento (modelo escola-professor atual). Estamos admitindo, a impossibilidade de criar, de viver inteligentemente, de desenvolver-se e principalmente de raciocinar. Digo raciocinar, pois, estamos esquecendo a função primeira da escola e do professor que é educar. Visto que, escola e professor são conseqüências da necessidade de se educar; e não o contrário, ou seja, a educação ser conseqüência da escola e do professor. Resumindo, quero expressar que a escola e o professor são apenas mecanismos utilizados para o processo educativo. Espero que a impressão que se tenha ao ler este parágrafo, não seja a de menosprezo ao professor ou à escola; mas, anseio que este, possa sim ser uma expressão da possibilidade de adaptação ou transformação dos professores e escolas, aos modelos culturais de cada povo. Acredito que os professores estão sensíveis ao que desejo expor.
Com isto, podemos discernir que o trabalho do psicólogo dentro das comunidades indígenas referente a educação pode ser dividido em duas categorias. Uma seria concernente a avaliação da estruturação das escolas e suas conseqüências; e a outra seria uma intervenção, no sentido de se fazer nestas escolas e educadores uma adequação do ambiente escolar a cultura, além de trabalhar os professores (já existentes, caso não se mude todo o ambiente) para uma preparação psicológica adequada para o contexto em que estes se encontram.

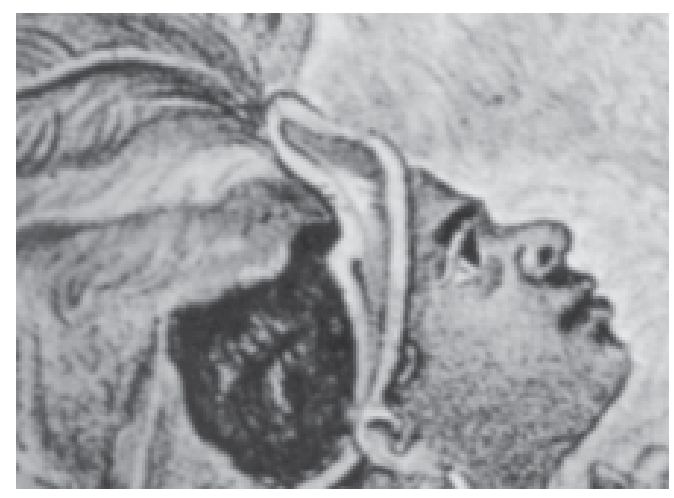

Assim, finalizamos este capítulo que tenta expor de forma compacta a necessidade da atuação do psicólogo dentro das comunidades indígenas. Esperamos que no processo de compactação deste, não tenha se comprometido o objetivo do mesmo. Estou ciente, ainda, que em muitos outros pontos poderia contribuir a Psicologia (em técnicas de ensino por exemplo), mas dado as limitações da ferramenta que utilizei-me (a monografia), contento-me com o exposto.

\section{Contribuição da Psicologia Fora das Comunidades Indígenas}

Enquanto no capítulo anterior a Psicologia dentro das comunidades indígenas pode contribuir tanto avaliando como intervindo no processo de escolarização (inclusão dos povos na educação), fora destas comunidades o trabaIho do psicólogo seria semelhante ao trabalho de um publicitário. Digo publicitário, pois, a atividade que este desempenharia seria uma atividade essencialmente de sensibilização (também pode ser dito, num certo sentido, educação dos povos não índios para o processo de educação indígena).
20 - Principalmente o psicólogo ambiental, que verifica o quanto existe reciprocidade entre 0 homem e seu ambiente, onde ambos se constroem e se transformam mutuamente. 
Novamente aqui o psicólogo social se enquadraria melhor na realização desta tarefa.

Uma das formas possíveis de atuação do psicólogo seria, por exemplo, a tarefa de arrancar a hipocrisia que reveste diversos meios quando procuram fazer suas contribuições humanitárias.

Sem se remeter ao cristianismo ${ }^{21}$, quero evidenciar aqui uma peculiaridade do termo que empreguei - contribuição humanitária -, pois, este não deve visar receber ou ganhar lucros em cima de trabalhos pseudo-filantrópicos. Mas, procurar, antes de tudo, a promoção humana do outro. Caso contrário, o termo passa a ser chamado de investimento humanitário, pois a contribuição nada tem de desinteressada (financeiramente).

Desta forma, venho colocar que é muito mais fácil contribuir e lutar por deficientes físicos e mentais, que possuem, na maioria dos casos, pais que arcam com suas despesas, que abraçar causas que quase não oferecem condições de sobrevivência por meio do trabalho desempenhado (por exemplo, o trabalho na educação indígena).

Quero frisar que mesmo sob tais circunstâncias (dificuldades financeiras), muitas Organizações Não Governamentais (Ongs), desempenham um belo papel. Para ilustrar podemos citar o Centro de Cultura Luís Freire, que mantém o Projeto Escola de Índio ${ }^{22}$.

Vale ressaltar que fora das comunidades indígenas, o trabalho, talvez, seja bem mais árduo do que pareça. Todavia a aplicabilidade da Psicologia é plenamente possível e inegável como auxílio no processo de inclusão da educação de qualidade e diferenciada verdadeiramente. Prova disto é a presente monografia - elaborada por um acadêmico de Psicologia Social -, ela tenta sensibilizar de todas as formas, de maneira a chamar a atenção, para o desafio da inclusão da educação diferenciada e institucionalizada dos povos índios.

24 - Grande Espirito da criação estão bem convosco os homens verdadeiros.
Por fim, como vimos, "a colheita é grande, mas poucos os operários! "23" Basta empenharse, trabalho não nos falta. Existe um leque de possibilidades de atuação fora das comunida- des. Espero que o narrado, sirva como uma seta, que indica novas estradas, tendo sempre em mente que, necessário se faz manter os olhos desvendados para que se siga o caminho que melhor convir.

\section{Conclusão}

Como foi visto, o primeiro capítulo desta obra tenta ampliar o conceito de educação inclusiva para que, com isto, possa-se percorrer livremente numa nova concepção de educação. Desta vez, aplicado à escolarização indígena.

Porém, não bastava apenas demonstrar esta possibilidade dentro do conceito de educação inclusiva. Era necessário ainda, um rápido rememoramento, com um novo olhar, no processo histórico de educação. Este rememoramento foi executado no capítulo dois desta monografia. Neste capítulo, verificamos que a educação sempre foi utilizada como arma destruidora dos povos indígenas. É o que se pode concluir após a leitura do mesmo, e reforça ao abrirmos o Aurélio (dicionário) e procurarmos a definição da palavra Guarani: "Indivíduo dos guaranis, cujos descendentes estão integrados à sociedade nacional".

Após uma nova construção da compreensão do termo educação inclusiva (no primeiro capítulo) e feita uma revisão no processo histórico de educação indigenista (capítulo dois), parti para o objetivo real do trabalho que era demonstrar não só a aplicação da psicologia na educação indígena, mas sua necessidade de atuação.

Neste trabalho, procurei ultrapassar os LIMITES impostos à definição de educação inclusiva, promovendo uma ampliação do mesmo de forma a obter-se uma nova PERSPECTIVA. Como conseqüência disto surgiu um novo DESAFIO: educação inclusiva e diferenciada. Para superação deste desafio, tentei recorrer a Psicologia. Esta Psicologia foi abordada de maneira a oferecer seu conhecimento enquanto ciência para um desenvolvimento de uma educação verdadeiramente de qualidade. Isto tudo foi colocado dentro de tais parâmetros, pois, acredito ser COMPROMISSO SOCIAL da Psicologia favorecer o progresso humano. 
De resto, lembro ainda que o narrado aqui não dê a impressão de uma atuação paternalista para com os povos indígenas. Pois, acredito já ser subentendido pelos profissionais, os quais me dirijo, a melhor maneira de lidar com situações adversas sem recorrer-se a atitudes indevidas.

Assim, fico na expectativa de que este trabaIho tenha oferecido de forma objetiva, uma nova abordagem da educação inclusiva. Além de demonstrar um campo jovem de atuação da Psicologia.
Reparar os erros do passado é sinal de sensatez, ignorá-los é prova de comodismo, vê-los e nada fazer é abominável.

\section{Tupã oicó endê yabê aba êté ${ }^{24}$}

Finalizo este trabalho lançando o convite especial (à classe na qual pretendo engajar-me), de juntos construírmos um mundo mais solidário e responsável, onde possa-se erguer o olhar ao horizonte e longe da hipocrisia sentir o peito cheio de esperança num mundo melhor.
Araújo, W. (1991). Estamos desaparecendo da terra, São Paulo: Bahá'í.

Dorin, L. (1989). Psicologia Educacional, $4^{\circ}$ ed., São Paulo: Editora do Brasil S.A.

Ferraz, S. Os guardiões do verde. in: Revista Veja., ed. Abril, Ano XXXI, n'26, 30 junho 1999. pg 152-160.

Freire, G.(1980). Casa-grande \& Senzala. 20ed., Rio de Janeiro: Brasil-América.

Jover , Ana. Inclusão: qualidade para todos. in: Revista Nova Escola. Ano XIV, n²123. junho 1999. pg 3-13.

Koogan, A. e Houaiss (1998). A. Enciclopédia e dicionário, $3^{\circ}$ ed., Rio de Janeiro: Seifor.

Lins, E. O Padre V. Gazeta de Alagoas, Maceió, 18 dezembro 1997. caderno B. pg 1.

Montejo, F. P. Leitura e escrita em sociedades indígenas. Porantim: em defesa da causa indígena, Brasília, agosto 1999. Ano XXI, n²17. pg 10.
Nova Escola. Ano XIV, n¹23, junho 1999.

Peralta, A. Nossa sabedoria pode preservar o mundo. Porantim: em defesa da causa indígena, Brasília, maio 1998. Ano XX, n²05. pg 5 .

Piletti, N. (1996).História do Brasil, $14^{\circ}$ ed., São Paulo: Ática.

Reimão, C.; Madureira, Virgílio. e Muñoz, M.L.(1978). Dicionário de Psicologia: as idéias, as obras, os homens, São Paulo: Verbo.

Ribeiro, D.(1987). O processo civilizatório: estudos de antropologia da civilização; etapas da evolução sócio-cultural. $9^{\circ}$ ed., Petrópolis: Vozes.

Roquette, J.P. (1928).Vocábulos Latinos, $2^{\circ}$ ed. Salvador: Editora Bomfim,

Souza, O. R.(1992). História do Brasil. Vol. 2, $19^{\circ}$ ed., São Paulo: Ática.

Suess, P. (1993). Cálice e cuia, 2ºd., Petrópolis: Vozes. 